\title{
Agricultura familiar em Moçambique: Características e desafios
}

\author{
Family farming in Mozambique: Characteristics and challenges \\ Agricultura familiar en Mozambique: Características y desafíos
}

Recebido: 02/05/2021 | Revisado: 10/05/2021 | Aceito: 13/05/2021 | Publicado: 28/05/2021

Mateus João Marassiro
ORCID: https://orcid.org/0000-0003-0871-4377
Universidade Lúrio, Brasil
E-mail: marassiro@ yahoo.com.br
Marcelo Leles Romarco de Oliveira
ORCID: https://orcid.org/0000-0003-2746-8407
Universidade Federal de Viçosa, Brasil
E-mail: marcelo.romarco@ufv.br
Geusa da Purificação Pereira
ORCID: https://orcid.org/0000-0002-6843-8071
Enstituto Federal de Educação, Ciência e Tecnologia Baiano, Brasil
E-mail: geusapereira@ hotmail.com

\begin{abstract}
Resumo
$\mathrm{O}$ artigo tem por objetivo apresentar o papel e os desafios da agricultura familiar em Moçambique. O estudo recorreu a revisão de literatura, para isso, foram usados artigos científicos, disponíveis no Google Scholar, publicados no período de 2000 a 2020, livros, relatórios técnicos e dissertações abordando matérias sobre agricultura, desenvolvimento rural e segurança alimentar. As análises feitas sugerem que a agricultura familiar é praticada pela maioria da população rural moçambicana e está voltada para o autoconsumo, caracterizado pela forte dependência da natureza e fraco uso de tecnologias. O país ainda enfrenta muitos desafios para o desenvolvimento rural, tanto que, ainda há muitas famílias passando por privações. As desigualdades no acesso às infraestruturas entre as regiões sul, centro e norte e entre os centros urbanos e o meio rural são bastante acentuadas. Com os resultados é possível apontar que as políticas agrárias moçambicanas se mostram inconsistentes deixando maior parte dos agricultores sem acesso a serviços e infraestruturas básicas que poderiam impactar na melhoria dos seus meios de vida. $\mathrm{O}$ estudo sugere que o governo moçambicano crie políticas mais robustas e exequíveis capazes de contribuir para a promoção do desenvolvimento rural, redução das assimetrias regionais e melhoria da qualidade de vida das famílias rurais.
\end{abstract}

Palavras-chave: Agricultura familiar; Moçambique; Desenvolvimento rural.

\begin{abstract}
The article aims to present the role and challenges of family farming in Mozambique. The study used articles, downloaded from Google Scholar published between 2000 - 2020, books, reports and dissertations addressing topics on agriculture, rural development and food security. The analyses suggest that family farming is practiced by the majority of the Mozambican rural population and is mainly for subsistence, characterized by strong dependence on nature and poor use of technologies. In general Mozambique faces many challenges for rural development, as many families are still experiencing hardship. Inequalities in access to infrastructure between the southern, central and northern regions and between the urban centers and the rural regions are quite pronounced. The literature review further point out that Mozambique agriculture policies are inconsistent, leaving most farmers without access to basic services and infrastructure that could have an impact on improving their livelihoods. The study suggests that the Mozambican government should create more robust and feasible policies capable of contributing to the promotion of rural development, reducing regional asymmetries and improving the quality of life of rural household.
\end{abstract}

Keywords: Family farming; Mozambique; Rural development.

\section{Resumen}

El artículo tiene como objetivo presentar el papel y los desafíos de la agricultura familiar en Mozambique. El estudio se realizó a través de la revisión de literatura científica; artículos publicados entre los años 2000 y 2020, encontrados a través del buscador Google Scholar, dissertación, así como libros y reportes de investigación sobre agricultura, desarrollo rural y seguridad alimentaria. Los análisis realizados sugieren que la agricultura familiar es practicada por la mayoría de la población rural de Mozambique y está dirigida al autoconsumo, caracterizado por una fuerte dependencia de la naturaleza y escaso uso de tecnologías. El país todavía enfrenta grandes desafíos para el desarrollo rural, que se reflejan en la gran cantidad de familias que viven con numerosas privaciones. Las desigualdades en el acceso a infraestructuras entre las regiones sur, centro y norte, como entre los centros urbanos y el medio rural, son muy acentuadas. Con los resultados de este artículo es posible apuntar que las políticas agrarias de Mozambique son 
inconsistentes, de tal manera que dejan a la mayor parte de los agricultores sin acceso a servicios e infraestructura básica que podrían significar una mejoría en sus medios de vida. El estudio sugiere que desde el gobierno se requiere la creación de políticas más robustas y accesibles, capaces de contribuir a la promoción del desarrollo rural, a la reducción de las asimetrías regionales y a la mejora de la calidad de vida de las familias rurales.

Palabras clave: Agricultura familiar, Mozambique, Desarrollo rural.

\section{Introdução}

$\mathrm{Na}$ África Subsaariana (ASS) ${ }^{1}$, cerca de $80 \%$ das famílias rurais consegue os seus rendimentos pela prática da agricultura em pequenas parcelas de terra, em média inferiores a 2 ha, com produção voltada para o autoconsumo e o excedente comercializado (Prakash, 2003; Davis, Di Giuseppe \& Zezza, 2017;). Desta forma, a ação dos agricultores está integrada na economia contribuindo com um terço do Produto Interno Bruto $\left(\mathrm{BIP}^{2}\right)$ do continente africano. Apesar desse potencial que a agricultura tem, ainda se percebe que os agricultores enfrentam enormes desafios, incluindo a insegurança alimentar, adaptação às mudanças climáticas, tecnologia não apropriada à realidade local e superação da pobreza.

Essa realidade está presente em Moçambique, um país que apresenta extensas áreas ou seja, são aproximadamente 36 milhões de hectares de terra aráveis, dos quais apenas 10\% em uso. O país apresenta ainda muitos recursos hídricos (rios, lagos e riachos) e condições agroecológicas que propiciam a pratica da atividade agrícola. Esse setor é descrito como de grande importância para a economia do país e é considerado a base de seu desenvolvimento (MINAG, 2010). Além disso, a agricultura emprega mais de $67 \%$ da população e contribui com cerca de $22 \%$ do PIB (INE, 2019). Essa atividade é praticada majoritariamente pelo setor familiar que ocupa cerca de $90 \%$ da área arável em uso, produzindo em parcelas pequenas (em média abaixo de 2 ha), com baixo uso de tecnologias modernas ou tecnologias não apropriadas as realidades desses agricultores. Destaca-se também, uma baixa cobertura dos serviços de assistência técnica e extensão rural (Ater). Ademais, esses serviços de Ater têm várias limitações, desde matérias, logísticas, recursos financeiros e humanos para alcançar maior número de agricultores (Marassiro, Oliveira \& Come, 2020; Sitoe, 2011; World Bank, 2019).

Esses fatores podem influenciar nos baixos níveis de produção e produtividade que constituem um denominador comum. Por conseguinte, influenciam também no aumento dos níveis de importação de alimentos. A baixa produtividade que caracteriza o setor agrícola e a vulnerabilidade a desastres naturais (seca, cheias, ciclones e inundações) impactam nos níveis de segurança alimentar e bem-estar das famílias. Desse modo, parte considerável da população moçambicana passa por momentos de crise e insegurança alimentar (Banco Africano de Desenvolvimento, 2018). Além disso, os programas e estratégias, do setor agrário do Ministérios de Agricultura e Desenvolvimento Rural, não conseguem mitigar esses problemas (Dadá, Nova \& Mussá, 2019).

Moçambique apresenta fortes evidências de disparidades de acesso a recursos e infraestruturas básicas, essa tendência é intensa nas regiões do centro e norte do país e, portanto, o cenário é mais acentuado nas zonas rurais. O governo vem reproduzindo as desigualdades regionais que foram iniciadas pelos portugueses na época colonial. Nesse período houve muitos investimentos na capital (sul do país) em detrimento das demais regiões. Isso reforça as desigualdades entre as zonas rurais e cidades (Cunguara, Garrett \& Donovan, 2013; World Bank, 2019). Por conseguinte, os níveis de pobreza, fome e insegurança alimentar são mais ressaltantes nessas regiões que foram sistematicamente marginalizadas.

\footnotetext{
${ }^{1}$ A ASS é a região do continente Africano situada ao sul do Deserto de Saara. É composta por seguintes países: África do Sul, Angola, Benin, Botsuana, Burkina Fasso, Burundi, Camarões, Cabo Verde, Chade, Congo, Costa do Marfim, Djibuti, Guiné Equatorial, Eritréia, Etiópia, Gabão, Gâmbia, Gana, Guiné, Guiné-Bissau, Ilhas Comores, Lesoto, Libéria, Madagáscar, Maláui, Mali, Mauritânia, Maurício, Moçambique, Namíbia, Níger, Nigéria, Quênia, República Centro-Africana, Ruanda, República Democrática do Congo (Ex-Zaire), São Tomé e Príncipe, Senegal, Seychelles, Serra Leoa, Somália, Sudão, Suazilândia, Tanzânia, Togo, Uganda, Zâmbia e Zimbábue.

${ }^{2}$ O PIB é uma medida de desenvolvimento econômico do nível macro, não considerando outras categorias que podem contribuir para o bemestar das pessoas.
} 
Essa situação, exige que reconheça o rural como um espaço dinâmico para além dos aspectos produtivos. Nesse contexto, Abramovay (2006) classifica o meio rural como um espaço que vai muito além da agricultura, e defende que a compreensão da dinâmica desse espaço exige que se analise a maneira como nele interagem os diferentes atores sociais para promover a pluriatividade e garantir que as famílias melhorem os seus meios de vida.

Podemos pensar, portanto, que o desenvolvimento, desses espaços devem levar em conta, mais que apenas recursos financeiros, compreende também o acesso à serviços básicos (alimentação, saúde, segurança, educação e outros). A limitação ou o não acesso a tais recursos impactam de modo significativo nas condições de vida das famílias, e, consequentemente, as colocam em situação de insegurança alimentar, especialmente, nas zonas rurais, afetando severamente àquelas que recorrem ao trabalho ocasional para o seu sustento. Diante do exposto, este artigo procura compreender qual o papel e desafios da agricultura familiar moçambicana e suas contribuições para a segurança alimentar do país.

\section{Metodologia}

Esse estudo recorreu a revisão de literatura para examinar questões a volta da agricultura, desenvolvimento rural e segurança alimentar em Moçambique. Neste sentido Gil, (1991); Garhardt e Silva (2009) consideram que esse procedimento metodológico usa livros, artigos científicos, relatórios, publicados por meios impressos e eletrônicos, página de web e sites, que abordam sobre um assunto, com objetivo de recolher conhecimentos sobre o tópico. Para tanto, foram usados vinte e cinco (25) artigos científicos, dez (10) relatórios técnicos, seis (6) livros e uma (1) Dissertação, esse material foi publicado no período entre os anos 2000 e 2020 abordando o tópico em estudo.

Os artigos analisados foram pesquisados no Google Scholar, utilizando as seguintes palavras-chave: a) desenvolvimento rural, b) o papel da agricultura no desenvolvimento rural, c) agricultura em Moçambique, d) acesso a serviços básicos e infraestruturas. Na busca, foram encontrados 45 artigos científicos. Após uma análise criteriosa dos resumos e considerações finais, concluiu-se que apenas vinte e cinco (25), discutiam assuntos relacionados ao tema e os restantes (vinte artigos) foram excluídos por não responderem à pergunta de pesquisa.

\section{Resultados e Discussão}

\subsection{Caracterização da agricultura e sua contribuição para o desenvolvimento rural}

Durante a ocupação territorial pelos portugueses (1895-1975), maior parte destes ficaram alojados no sul do país, tornando esta região a mais urbanizada e com maior acesso a infraestruturas. Devido as condições agroecológicas, que as regiões do centro e norte apresentam, atraíram as grandes empresas agrárias dedicadas a produção de culturas industriais (sisal, algodão e chá). Por sua vez, os agricultores familiares eram responsáveis pela produção de culturas alimentares. Essas companhias agrárias, produziam com a finalidade de exportar os produtos para alimentar a indústria, usando os portos da região norte de Moçambique. Essa situação impactou nos investimentos ferroviários e rodoviários do interland para a costa e poucos investimentos foram alocados para ligar o norte ao sul do país (Cunguara, Garrett \& Donovan, 2013).

Com o regime socialista adotado após a independência nacional em 1975, a terra foi nacionalizada, e mais de 2000 explorações agrárias foram abandonadas pelas empresas coloniais (Gemo, 2009; Mosca, 2017). Segundo Mosca (2017), no período entre 1976 e 1982 recursos financeiros, equipamento mecânico, insumos agrícolas melhorados e pessoal técnico foram alocados às Empresas Agrárias Estatais (EAE). E, estas desenvolveram as primeiras ações relacionadas à extensão rural sob forma de cooperativas agrárias no âmbito da socialização do campo e pelos centros de desenvolvimento rural do Ministério de Agricultura (MINAG). 
Assim começavam as primeiras ações de extensão rural em Moçambique. Esse marco de formalização dos serviços de Ater foi no ano de 1987, porém, devido a Guerra Civil, estes serviços tiveram seu funcionamento precarizado e sendo de fato retomado de forma efetiva e no âmbito nacional após a assinatura do Primeiro Acordo Geral de Paz em 1992 (Marassiro; Oliveira \& Come, 2020).

A extensão rural disponibiliza informação proveniente da pesquisa acadêmica local e global ajudando os agricultores na sua organização e gestão da propriedade, no desenvolvimento de habilidades, e melhoria nas suas decisões contribuindo nos meios de vida dos agregados familiares e na segurança alimentar (Baloch \& Thapa, 2018; Faure, Desjeux \& Gasselin, 2012; Norton \& alwang, 2020). Porém o direcionamento da Ater tende a modernizar do setor agrário, tomando como base os resultados da pesquisa e, os agricultores familiares caracterizados majoritariamente por apresentarem recursos escassos, não chegam a ser beneficiários efetivos desses serviços.

Para o caso de Moçambique esses serviços funcionam com certa descoordenação institucional, limitações orçamentárias e de recursos humanos. Parte do orçamento é proveniente das organizações internacionais como Fundo Monetário Internacional (FMI) e Banco Mundial. Essa dependência em recursos tem impactado no acesso a esses serviços pelos agricultores. Em 2015 cerca de 4,3\% dos agricultores do setor familiar recebeu visitas de extensionista, e 0,4\% se beneficiou de crédito para as atividades relacionadas com agricultura e cerca de 5\% usou fertilizantes químicos (Guanziroli \& Guanziroli, 2015; Mabiso, Cunguara \& Benfica, 2014; MASA, 2014; MASA 2015). Cerca de 67\% (18,7 milhões) da população moçambicana vive no meio rural e, está engajada no setor agrário que se dedica majoritariamente a produção para autoconsumo (INE, 2019).

Cunguara (2012), Mosca (2014) e Mosca (2017) sustentam que os agricultores familiares foram sistematicamente marginalizados por esses serviços. Portanto, diversos fatores contribuem para essa realidade, entre eles destaca-se a fraca cobertura e treinamento dos técnicos, escassez de recursos, cadeia de valor ineficiente, fraca qualidade das infraestruturas rodoviárias e de conservação de produtos agrários, falhas do mercado, o acesso a serviços de extensão, a baixa escolaridade, o aceso ao crédito. A decisão para usar uma tecnologia é muitas vezes o resultado de comparação de benefícios e incentivos da nova tecnologia, ou seja, comparando custos e benefícios da mesma (Cunguara \&Thompson, 2018; Marassiro, oliveira \& come, 2020; Uaiene, 2011).

No que concerne ao funcionamento dos serviços de extensão e investigação agrária, Mosca (2017) aponta que o orçamento alocado neste setor, é de cerca de $0,24 \%$ do PIB Agrário, o que corresponde a três vezes menos que a média na ASS. Essa exiguidade orçamentária evidencia o incumprimento da declaração de Maputo (de 2003) que orientava que cada país africano deveria alocar 10\% do seu orçamento ao setor agrário. Fan, Omilola e Lambert (2009) apontam que os países da ASS não foram capazes de cumprir a meta de $10 \%$. Por via disso e de outros fatores já mencionados, Moçambique é classificado por Kassie et al. (2012) como sendo o país que apresenta o rendimento mais baixo de milho ( 0,7 ton/ha) quando comparado com Angola, Malawi, Zâmbia e Zimbábue com rendimentos acima de 1 ton/ha.

Apesar dos desafios que o setor agrário moçambicano enfrenta, apresenta uma contribuição significativa na economia do país. No período entre 2003 e 2008, o PIB agrário variou entre 5,2 e 11,6\%, sendo que o PIB superior a 10\% foi registado entre os anos 2006 e 2008. Moçambique, embora registre taxas de crescimento econômico, ele ainda é um dos países mais pobres do mundo, pela classificação do Programa das Nações Unidas, baseados no PIB e no Índice de Desenvolvimento Humano- IDH. Esse cenário econômico exige do governo uma maior transparência, articulação setorial e o estabelecimento de incentivos e políticas orientadas aos agricultores do setor familiar (Cunguara \& Halon. 2010).

Jayne, Mather e Mghenyi (2010) consideram que não há futuro para os agricultores familiares africanos se os governos desse continente não adotarem políticas e investimento necessários para que esse setor seja o verdadeiro catalizador do desenvolvimento. A exemplo disso, a produtividade das culturas no continente africano encontra-se estagnada nos últimos 
40 anos. Para melhorar os níveis de produção junto dos agricultores desses países e reduzir a fome e pobreza, torna-se relevante o aprimoramento dos conhecimentos e experiências geracionais destes sujeitos nos seus processos de reprodução social.

\subsection{Os conhecimentos dos agricultores locais nos processos de produção}

A modernização da agricultura baseada na tecnologia industrializada pode não gerar resultados desejados porque, em muitas situações desconsideram as realidades locais, além disso os agricultores avaliam as suas condições econômicas e sociais antes de tomar certa decisão, o que pode comprometer essa modernização. Pela necessidade de mudanças nas bases produtivas e da aquisição dessa tecnologia, essa transformação pode induzir o agricultor a recorrer ao endividamento, que, na maioria dos casos, é insustentável para os agricultores do setor familiar devido as taxas associadas ao risco da atividade agrícola sobretudo quando esta é praticada dependendo das condições agroclimáticas de cada região. Um dos mecanismos para tornar a tecnologia facilmente adotável pelos agricultores seria através das tecnologias sociais ${ }^{3}$ que tornam os agricultores atores ativos no processo, adequando a tecnologia a diferentes fatores socioculturais e ecológicos dos agricultores (Adenle, Wedig \& Azadi, 2019; Knickel et al., 2018).

O Ministério de Agricultura e Segurança Alimentar de Moçambique (MASA, 2015) aponta que apesar da introdução de programas destinados a aumento da produção e produtividade, o baixo uso de tecnologias agrárias pelos agricultores, contribui negativamente nos processos produtivos. O fraco uso destas, pode estar associado, por exemplo, pela falta de condições sociais, econômicas, culturais dos agricultores, uma vez que a importação de técnicas majoritariamente de base industrial exige do agricultor altos investimentos e a necessidade de um acompanhamento técnico especializado. Nesse contexto, Coelho (2014) aponta que a modernização da agricultura pelo uso da tecnologia industrializada tende a desconectar os agricultores do seu ambiente produtivo e do seu repertório sociocultural, desconsiderando na maioria das situações as realidades locais.

Uma forma de mitigar essa situação seria considerar as questões sociais e culturais das comunidades rurais, bem como envolver esses agricultores nesse processo de transformação. Esse cuidado seria fundamental antes de se implementar um programa de inovações tecnológica. Entretanto, isso requer que as equipes de extensão rural ou os responsáveis por essas mudanças estejam atentos, preparados e com recursos para intervir, levando em conta essas realidades locais (Marassiro, Oliveira \& Come, 2020).

De acordo com Otte et al. (2018) a participação dos agricultores ajuda a identificar as necessidades tecnológicas e pode promover intercâmbio e criação de diferentes conhecimentos para desenvolvimento de tecnologia agrícola apropriada a realidade do local. Jayne, Mather \& Mghenyi (2010) argumentam que a transformação agrícola pode ser realizada se os atores de geração de tecnologias estiverem atentos aos contextos que se propõem uso de tais tecnologias. Portanto, a produção e difusão de tecnologias com a participação dos agricultores, pode contribuir com mais afinco para que ocorra maior apropriação das técnicas e/ou tecnologia desde que seja considerada essas particularidades sociais, culturais e econômicas das comunidades objeto desses programas de modernização (Dagnino, 2019).

Em países da África, para que a agricultura possa laborar de modo eficiente é necessário a reforma do governo de cada país, a busca de doadores internacionais e a integração do ambiente de comércio internacional. Isso exigirá liderança esclarecida em todas as frentes, assim como, um ambiente político favorável. As reformas devem ser formuladas tendo em consideração os recursos e as condições agroecológicas de cada país ou região (Jayne, Mather \& Mghenyi, 2010).

\footnotetext{
${ }^{3}$ As tecnologias sociais compreendem um conjunto de técnicas e metodologias transformadoras, desenvolvidas e/ou aplicadas na interação com a população e apropriadas por ela, que representam soluções para inclusão social e melhoria das condições de vida (Instituto De Tecnologia Social, 2007).
} 
Para o caso de Moçambique, embora a agricultura seja considerada um dos pilares da economia, entretanto, nota-se que as políticas não estão bem ajustadas para tornar o setor agrário mais produtivo, robusto e dinamizador do desenvolvimento rural (Guanziroli \& Guanziroli, 2015; Mabiso, Cunguara \& Benfica, 2014; MASA, 2014; MASA, 2015). A participação dos agricultores no desenho das políticas do setor, assim como na adaptação das tecnologias às suas condições sociais e econômicas ainda é bastante fraca (Marassiro, Oliveira \& Come, 2020). Por sua vez Moura \& Rosário (2016) destacam a necessidade de uma agricultura familiar mais dinâmica para que possa alcançar o progresso e bem-estar nas próximas décadas. Porém, com as limitações que o setor enfrenta exige um esforço redobrado do governo e outros atores na promoção do desenvolvimento rural.

\subsection{Desafios estruturais do meio rural moçambicano e suas interferências na agricultura}

O meio rural é caracterizado pela forte relação com a natureza, áreas menos povoadas, voltadas principalmente, para a produção agrícola e com forte dependência dos serviços urbanos (Favareto \& Berdegué, 2018; Freitas, Freitas \& Dias 2012). A marginalização rural está geralmente associada a essa localização geográfica remota, a dominância do setor primário (agricultura), precariedade de infraestruturas em termos de estradas e serviços públicos, que acabam impactando nas transações econômicas (Bock, [s.d.]). A existência de infraestruturas de qualidade é fundamental para dinamizar um conjunto de atividades praticada pelos residentes incluindo agricultura e a aproximação entre o meio rural e urbano influenciando nos sistemas de comercialização entre os dois espaços e contribuindo para o desenvolvimento rural.

Para o caso de Moçambique as infraestruturas como estradas e armazéns de conservação de grão e outros meios de conservação de produtos agrários têm contribuído negativamente para o desenvolvimento do meio rural. A sua ineficiência aumenta a distância entre a cidade e o meio rural, outro sim, aumentam os custos de transação. Maior parte dos agricultores moçambicanos comercializam os seus excedentes logo após a colheita na porta da unidade de produção a preços mais baixos influenciado pela fraca capacidade de armazenamento e excesso de necessidades básicas. Essa situação tende a colocar os agricultores em desvantagem e de alguma maneira excluídos do processo de desenvolvimento.

É fundamental um sistema de vias de acesso de boa qualidade que permita a interface entre o rural e urbano. Knickel et al. (2018) apontam que o fortalecimento de laços com cidades próximas a zona rural pode impulsionar o alcance de maior resiliência através da cooperação entre agricultores e intervenientes provenientes das cidades. Para Sabourin (2016) a agricultura constitui uma atividade que interconecta entre o setor e o território apoiando o desenvolvimento rural, tanto que inclui novas atividades não agrícolas e investimentos públicos.

No período entre 2008 e 2015, Moçambique aumentou os níveis de investimento público, por isso, o país registou um crescimento e uma tendência de redução da pobreza, porém as desigualdades entre as zonas rurais e urbanas aumentou, limitando oportunidades para os pobres melhorarem os seus padrões de vida. As regiões centro e norte registaram fraco progresso, sobretudo nas zonas rurais no que diz respeito a acesso a água potável, eletricidade, estradas, mercado, escola primária e instalações sanitárias. As províncias de Zambézia, Nampula e Tete, estão muito atrasadas quanto ao aceso e estão com dificuldades de recuperar. A primeira apresenta maior taxa da população abaixo da linha da pobreza (World Bank, 2019).

Ao analisar alguns indicadores socioeconômicos em Moçambique, observa-se que no período entre 1997 e 2014 a taxa nacional de analfabetismo baixou de 60,5\% em 1977 para 39\% em 2017; a expectativa de vida aumentou de 42,3 anos para 53,7 anos no período entre 1977 e 2017; e o número de habitação de palhota reduziu de 69,8\% para 47,4\% entre 2007 e 2017. De forma geral os dados mostram sinal de alguma evolução dos indicadores socioeconômicos. O analfabetismo (39\%) constitui um grande desafio para o governo moçambicano, portanto, este sector influencia noutras esferas, sobretudo nos processos inerentes ao desenvolvimento e bem-estar dos agregados familiares. Somado ao analfabetismo, o fraco 
funcionamento do sistema de saúde dentre outros fatores, podem ser algumas razões das altas taxas de natalidade, mortalidade e mortalidade infantil (Cândido, 2010; INE, 2019).

$\mathrm{O}$ acesso a serviços básicos ainda constitui um desafio para os moçambicanos, a situação tende a ser mais crítica nas zonas rurais. Por conseguinte, a população que reside nessas zonas está sujeita a sobrevier em condições precárias. De acordo com dados do World Bank (2019), o acesso a eletricidade e água no país ainda continua baixo, com uma média de $27 \%$ e $26 \%$ respectivamente dos agregados familiares. Foram analisadas algumas privações dos moçambicanos que residem no meio rural aprestados na Figura 1. Essas privações caracterizam o meio rural moçambicano no período de 1997 a 2014 . A limitada possibilidade de aceder aos serviços pelo cidadão, tende a influenciar no seu bem-estar.

Figura 1: Prevalência de privação no meio rural moçambicano (1997 a 2014).

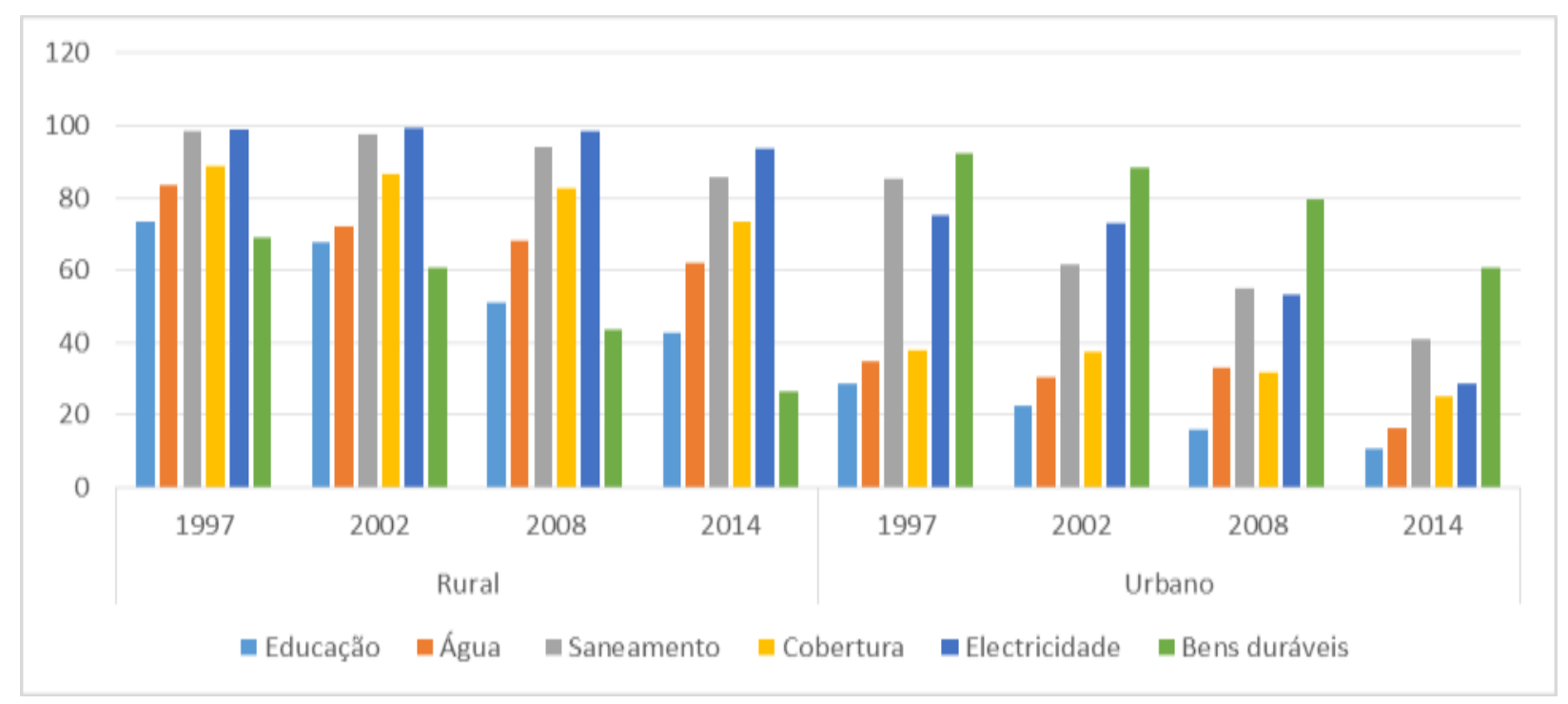

Fonte: Moura e Rosário (2016)

Os dados elucidam que a zona rural apresenta altos índices de privação comparativamente a zona urbana. Embora apresentem uma tendência de redução, o aceso a eletrificação ainda constituí uma privação para maior parte dos moçambicanos, até 2014 cerca de $90 \%$ da população rural moçambicana estava privada de acesso à energia eclética, e cerca de 29\% nas acidades. A privação a água potável também constitui uma maior preocupação, pois até 2014 cerca de $60 \%$ dos moçambicanos estava privada de acesso a este recurso no meio rural e cerca de $8 \%$ no meio urbano. A privação a educação até 2014 era bastante expressiva no meio rural. Os dados mostram uma discrepância acentuada entre o meio rural e urbano e exige do governo um esforço redobrado para reverter a situação atual que os moçambicanos estão sujeitos. Por outro lado, essas privações, limitam as possibilidades de promoção de iniciativas inerentes a pluriatividades e ampliação dos meios de vida e do alcance do bem-estar dos agregados familiares.

Paradoxalmente aos níveis de privação com relação ao acesso a eletricidade apresentados anteriormente, Moçambique apresenta o potencial mais alto a nível do continente africano. O país produz 2600 MW no entanto, consome apenas $900 \mathrm{MW}$ o excedente é exportado para os países vizinhos (África do Sul e Zimbábue). Apesar disso apenas 29\% da população tem acesso à energia elétrica da rede nacional, sendo que o desafio é levar a energia as zonas rurais (Banco Africano de Desenvolvimento, 2018).

De acordo com o World Bank (2019) houve um aumento de acesso a saúde e água. Porém, o acesso a transporte, mercado e escolas baixou, sobretudo nas zonas rurais. $\mathrm{O}$ aumento das infraestruturas que o país foi registando para assegurar o 
acesso das populações as mesmas, foi se reproduzindo as disparidades entre o sul e o resto do país. $\mathrm{O}$ fraco acesso a infraestruturas no centro e norte aumentou as desigualdades e diferenças de oportunidades pelas famílias pobres.

Com o objetivo de contribuir para a redução das desigualdades e da pobreza, o governo moçambicano desenhou e implementou os Planos de Ação para a Redução da Pobreza Absoluta (PARPA). O PARPA I foi implementado no período de 2001 - 2005 e o PARPA II no período de 2006 - 2010. De forma geral os PARPAs tinham como objetivo reduzir a pobreza absoluta e, a agricultura sempre teve uma certa prioridade nesses instrumentos de desenvolvimento. Os PARPAs (2006-2008, 2009) consideram que os objetivos que Moçambique estabeleceu para a sua política de redução de pobreza, eram bastante ambiciosos. Nesse período a pobreza saiu de 69\% em 1996/1997 para 54\% em 2002/2003.

A análise estatística dos dados de 1996 a 2014, do Ministério da Economia e Finança (MAF) a 95\% de significância verifica-se uma diferença estatisticamente significativa na redução da pobreza no período de 1996 para 2002 (p-value 0,000). No entanto, nos demais anos a redução não foi significativa. Em 1996 a incidência da pobreza era forte nas províncias de Inhambane, Sofala, Tete e Niassa. No ano 2002 a pobreza absoluta teve tendência ainda forte nas províncias de Inhambane, Tete e Cabo Delgado. Portanto, até no ano de 2014 as províncias de Gaza, Zambézia, Nampula e Niassa continuavam com taxas de redução da pobreza ainda muito fracas. A diferença significativa na taxa da redução da pobreza a nível nacional registada entre os anos 1996 e 2002 pode ter sido influenciada por outros fatores, pois o PARPA I tinha apenas um ano de implementação. De forma geral pode se afirmar que os PARPAs I e II não foram capazes de reduzir a pobreza tal como estava previsto.

Assim, segundo o World Bank (2019) é necessário promover um equilíbrio de investimentos entre as regiões sul, centro e norte tanto como, entre o meio rural e urbano. Cerca de $51 \%$ do crescimento econômico de Moçambique no período entre 2008 e 2018, foi agregado nas cidades. Ademais, a taxa de crescimento populacional urbana aumentou de 3,3\% entre 1997-2007 para 3,9\% entre 2007 e 2017, exigindo assim o aumento de investimentos para responder a demanda. Porém, o crescimento urbano enfraquece o crescimento rural devido a fraca oferta de mão de obra (para agricultura) nas áreas rurais fragilizando o seu desenvolvimento. Por outro lado, reduz a matéria prima para a agroindústria, por consequência, o preço dos produtos agrários aumenta reduzindo o bem-estar nas cidades e vilas.

Por outro lado, a rápida urbanização desviando investimentos públicos das áreas rurais para investir nas cidades penaliza o bem-estar das populações pobres que residem nesse meio e dos extratos pobres que residem nas cidades. De forma geral os investimentos não têm acompanhado suficientemente o crescimento populacional, tanto é que parte significativa da população moçambicana enfrenta situações de insegurança alimentar.

\section{Considerações Finais}

A agricultura moçambicana é caracterizada por muitos desafios, resultando em baixa produção e produtividade. Essa atividade é praticada maioritariamente por agricultores do setor familiar com recursos bastante limitados. Os serviços de extensão rural têm uma cobertura muito fraca, influenciada por insuficiência de recursos financeiros, materiais e humanos. Os agricultores não têm recursos suficientemente para adotar certas tecnologias, assim seria relevante adaptá-las às condições econômicas, sociais e agroecológicas. Portanto, as técnicas devem ser socialmente desenvolvidas envolvendo os agricultores de cada região, sendo a tecnologia social uma importante alternativa.

A consideração dos conhecimentos dos agricultores pode permitir que cada região ou distrito desenvolva tecnologias mais ajustadas ao conjunto de elementos que caracteriza tanto os agricultores quanto das condições agroecológicas. Outrossim, permite maior socialização do meio rural com os centros urbanos, portanto, é fundamental a existência de infraestruturas como estradas, armazéns e outras que ajudem os agricultores nos seus processos produtivos e na promoção do desenvolvimento rural. 
As infraestruturas de índole social promovem o desenvolvimento do capital humano. $\mathrm{O}$ trabalho sugere que Moçambique precisa investir nas zonas rurais, e, de forma geral, nas regiões centro e norte para reduzir as desigualdades e diminuir as assimetrias no acesso a infraestruturas e promover um desenvolvimento equilibrado. Os resultados sugerem que os programas e estratégias de redução de pobreza implementados pelo governo Moçambicano não foram bem-sucedidos.

A disponibilização de tecnologias adaptadas as condições sociais, econômicas e ecológicas associadas a acesso a infraestruturas e energia elétrica ou de fontes alternativas podem impulsionar os agricultores para que possam aumentar os seus níveis de produção e diversificar a sua renda. O acesso à educação e saúde pode aumentar o domínio das práticas de produção de alimentos de qualidade e com valor nutricional e suprir as necessidades alimentares e nutricionais das suas famílias. Para isso acontecer o Governo moçambicano deve investir na infraestrutura, recursos humanos qualificados e um quadro político coerente e exequível num processo democrático e participativo. Por outro lado, devem ser criados mecanismo de adaptação e superação a eventos extremos que ciclicamente ocorrem no país.

Sugerimos que trabalhos futuros discutam de forma aprofundada sobre a importância da valorização dos conhecimentos autóctones nos processos de reprodução social e no desenvolvimento rural de Moçambique.

\section{Agradecimentos}

O autor principal agradece a CAPES pela bolsa oferecida para o seu doutorado no Programa de Pós-graduação (PECPG) EDITAL 2018, processo $\mathrm{n}^{\circ}$ 88881.284148/2018-01. Agradece ainda a Prof. ${ }^{a}$ Nathália Thais Cosmo da Silva, que despertou a atenção de escrever esse artigo.

\section{Referências}

Abramovay, R. (2006). Para uma teoria dos estudos territoriais. Desarrollo rural: organizaciones, instituciones y territorios.

Adenle, A. A., Wedig, K. \& Azadi, H. (2019). Sustainable agriculture and food security. In Africa: The role of innovative technologies and international organizations. Technology in Society Sustainable. V. 58 (1), 17.

Baloch, M. A. \& Thapa, G. B. (2018). The effect of agricultural extension services: Date farmers' case in Balochistan, Pakistan. Journal of the Saudi Society of Agricultural Sciences. 17 (3), 282-9.

Banco Africano De Desenvolvimento. (2018). Resumo dos resultados 2018..

Bock, B. B. [s.d.] Rural Marginalisation and the Role of Social Innovation, A Turn Towards Nexogenous Development and Rural Reconnection. V. 56 (4).

Cândido, M. C. de A. (2010). Desenvolvimento sustentável e pobreza no contexto de globalização. O caso de Moçambique. Dissertação de Mestrado em Ciências Politicas e Relaçoes internacionais.

Coelho, T. M. G. (2014). A arte das orientações técnicas no campo: concepções e métodos. Etnoikos, (2a ed.).

CONDRAF. Conselho Nacional De Desenvolvimento Rural Sustentável (2013). Documento de Referência. Brasília. $2^{\circ}$ Conferência Nacional de Desenvolvimento Rural Sustentável e Solidário.

Cunguara, B. (2012). An exposion of development failure in Mozambique. Review of African Political Economy. 39 (131), $161-171$.

Cunguara, B., Garrett, J. \& Donovan, C. (2013). Análise situacional, constrangimentos e oportunidades para o crescimento agrário em Moçambique. Relatório de pesquisa $73 \mathrm{P}$.

Cunguara, B. \& Hanlon. J. (2010). O fracasso na redução da pobreza em Moçambique. Working Papers Series no 74 (2), 1-33.

Cunguara, B. \& Thompson. T. (2018). Mozambique: Desk Study of Extension and Advisory Services. Developing Local Extension Capacity (DLEC) Project.

Dadá, Y. A., Nova, Y. \& Mussá, C. (2019). Investimento Público Na Agricultura: O caso dos centros de prestação de serviços agrários, complexo de silos da bolsa de mercadorias de Moçambique e dos regadios. Observador Rural. (81), 43.

Dagnino, R. (2019). Tecnociência solidária um manual estratégico. Editora Lutas anticapital.

Davis, B., Giuseppe, S. \& Zezza, A. (2017). Are African households (not) leaving agriculture? Patterns of households' income sources in rural Sub-Saharan Africa. Food Policy. 67, 153-174.

Fan, S., Omilola B. \& Lambert M. (2009). Public spending for agriculture in Africa: Trend and cooperation. Resakss working paper n $^{\mathbf{2}} 28$ 
Faure, G., Desjeux, Y. \& Gasselin, P. (2012). New Challenges in Agricultural Advisory Services from a Research Perspective : A Literature Review, Synthesis and Research Agenda. The Journal of Agricultural Education. 18 (5), 461-491.

Favareto, A. \& Berdegué, J. (2018). Mudanças globais e locais - implicações para o futuro do enfoque territorial do desenvolvimento rural na América Latina. p.1-22.

Freitas, A. F. de, Freitas, A. F. de \& Dias M.M. (2012). Mudanças conceituais do desenvolvimento rural e suas influências nas políticas públicas. REVSTA. 46 (6), 1575-1598.

Gemo, H. (2009) Extensão Rural em Moçambique: Evolução, desafios e perspectivas (1975-2006): in Politicas Publicas e Desenvolvimento Rural: Percepções e Prespectivas no Brasil e em Mocambique. Porto Alegre.

Gerhard, T. E. \& Silveira D. T. (2009). Métodos de pesquisa. Universidade do Rio Grande do Sul.

Gil, A. C. (1991). Como elaborar projeto de pesquisa. (3a ed.), Editora Atlas.

Guanziroli, C. E.\& Guanziroli. T. (2015). Modernização da Agricultura em Moçambique: determinantes da renda agrícola. Piracicaba-SP. (53), 115-128.

INE- Instituto Nacional De Estatistica. (2019). Resultados Definitivos. Censo 2017.

ITS- Instituto de Tecnologia Social. (2007). Conhecimento e Cidadania I: Tecnologia Social.

Jayne, T. S., Mather, D. \& Mghenyi, E. (2010). Principal Challenges Confronting Smallholder Agriculture in Sub-Saharan Africa. World Development. V. 38 (10), 1384-1398.

Kassie, G. T., Erenstein O., Mwangui W., LaRovere R., Setimela P. \& Langyintou A. (2012) Characterization of Maize Production in Southern Africa: Synthesis of CIMMYT/DTMA Household Level Farming System Surveys in Angola, Malawi, Mozambique, Zambia and Zimbabwe.

Knickel, K., Redman, M, Darnhofer, I., Ashkenazy, A., Chebach T. C., Sumana, S., Tisenkopfs T., Zemeckis, R., Atkociuniene, V., Riveira, M., Strauss, A., Kristensen, L. S., Schiller, S., Koopmans, M.E. \& Rogge E. (2018) Between aspirations and reality : Making farming, food systems and rural areas more resilient, sustainable and equitable. V. 59.

Marassiro, M. J., Oliveira, M. L. R. de \& Come, S. F. (2020). Three Decades of Agricultural Extension in Mozambique: Between Advances and Setbacks. Journal of Agricultural Studies. V. 8 (2), 418-439.

MASA. Ministério da Agricultura e Segurança Alimentar. (2014). Anuário de Estatísticas Agrárias.

MASA. Ministério da Agricultura e Segurança Alimentar (2015) Anuário de Estatísticas Agrárias.

MINAG. Ministério de Agricultura. (2010). Plano Estratégico para o Desenvolvimento do Sector Agrário - PEDSA.

Mendonça, D., Procópio, D. P. \& Corrêa, S. R. (2019). A contribuição das indicações geográficas para o desenvolvimento rural brasileiro. Research, Society and Development. .8, 1-18.

Mosca, J. (2012). Agricultura familiar em Moçambique: ideologias e políticas. CESA. Working paper 127.

Mosca, J. (2017). Agricultura familiar em moçambique: ideologias e políticas. Revista Nera. (38), 68-105.

Moura, J. S. P. \& Rosário N. M. (2016). O papel dos serviços financeiros rurais na promoção do desenvolvimento da agricultura familiar: caso da Cooperativa 25 de Setembro no distrito de Boane, Sociedade e território. 28 (2), 42-56.

Norton, G. W. \& Alwang, J. (2020). Changes in Agricultural Extension and Implications for Farmer Adoption of New Practices. Applied Economic Perspectives and Policy. 42 (1), 8-20.

Otte, P. P., Bernardo, R., Phinney, R., Davidsson, H. \& Tivana, L. D. (2018). Facilitating integrated agricultural technology development through participatory research. Journal of Agricultural Education and Extension. 24 (3), 285-299.

Prakash, D. (2003). Director ICA-Japan Agricoops Management Training Project for Asia. America, n. February.

Sabourin, E. \& Texeira, O. A. (2002). Planejamento e Desenvolvimento dos Territórios Rurais. Conceitos, controvérsias e experiências. Embrapa informação tecnológica.

Sitoe, T. A. (2011). A Nova Revolução Verde Africana: de que forma ela pode contribuir para erradicar a fome e a pobreza na África. Desenvolvimento em Questão. 8 (15), 239-273.

Uaiene, R. (2011). Determinantes para a Adopção de Tecnologias Agrícolas em Moçambique. Fsg.Afre.Msu.Edu.

WORLD BANK. (2019). Desigualdades Espaciais No Acesso a Infraestruturas Básicas. Orientação para o programa de investimento público de Moçambique. 